\title{
Structural vulnerabilities and HIV risk among sexual minority female sex workers (SM-FSW) by identity and behavior in Baltimore, MD
}

Jennifer L. Glick ${ }^{1 *}$ (D), Sahnah Lim¹,2, S. Wilson Beckham¹, Catherine Tomko ${ }^{1}$, Ju Nyeong Park ${ }^{1}$ and Susan G. Sherman ${ }^{1}$

\begin{abstract}
Background: Research suggests sexual minority female sex workers (SM-FSW) face elevated structural vulnerability and HIV risk compared to their heterosexual counterparts. Structural vulnerabilities reflect societal level factors (e.g., sexism, homophobia, racism) that constrain an individual's agency, particularly related to health outcomes. This study examines the association between SM status by identity and behavior, structural vulnerability, and HIV risk among a sample of street-based FSW.
\end{abstract}

Methods: The current study utilizes baseline data from the SAPPHIRE study, a prospective cohort of cis gender and transgender FSW in Baltimore, MD, recruited through targeted time-location sampling from April 2016 to January 2017. The current analysis focuses on cisgender women. The baseline survey ascertained demographics, substance use, intimate partner violence (IPV), and sex work characteristics. Multivariable models were constructed using selfidentity and behaviorally defined SM status as independent variables with vulnerability outcomes (e.g., injection drug use, injection speedball, binge drinking, homelessness, physical IPV, ever had a pimp, and being a minor at sex work entry (age < 18)) as dependent variables.

Results: Of the participants ( $n=247), 25.5 \%(n=63)$ self-identified as a SM by identity (e.g., gay or bisexual), and $8.5 \%(n=21)$ reported SM behavior (e.g., same-gender sexual behavior) in the past 3 months. In multivariable logistic regression models, SM status by identity was associated with increased odds of injection drug use, binge drinking, homelessness, physical IPV, and being a minor at sex work entry. SM status by behavior was associated with increased odds of binge drinking, homelessness, ever having a pimp, and being a minor at sex work entry.

Conclusion: The study indicates disproportionate structural vulnerability and heightened HIV risk among SM-FSW, as compared to their heterosexual counterparts, with differences in their profile by sexual identity and behavior. Findings suggest a need for nuanced interventions tailored to these populations.

Keywords: Vulnerability, Sexual minority women (SMW), Female sex workers (FSW), HIV risk

\footnotetext{
*Correspondence: jglick5@jhu.edu

'Department of Health Behavior and Society, Johns Hopkins Bloomberg

School of Public Health, Baltimore, MD 21205, USA

Full list of author information is available at the end of the article
}

\section{$\triangle B M C$}

(c) The Author(s). 2020 Open Access This article is licensed under a Creative Commons Attribution 4.0 International License, which permits use, sharing, adaptation, distribution and reproduction in any medium or format, as long as you give appropriate credit to the original author(s) and the source, provide a link to the Creative Commons licence, and indicate if changes were made. The images or other third party material in this article are included in the article's Creative Commons licence, unless indicated otherwise in a credit line to the material. If material is not included in the article's Creative Commons licence and your intended use is not permitted by statutory regulation or exceeds the permitted use, you will need to obtain permission directly from the copyright holder. To view a copy of this licence, visit http://creativecommons.org/licenses/by/4.0/. The Creative Commons Public Domain Dedication waiver (http://creativecommons.org/publicdomain/zero/1.0/) applies to the data made available in this article, unless otherwise stated in a credit line to the data. 


\section{Background}

Female sex workers (FSW) who are also sexual minorities (SM-FSW) face greater structural vulnerabilities, which exacerbate their HIV risk, compared to their heterosexual counterparts [1-4]. Structural vulnerabilities reflect societal-level factors (e.g., sexism, homophobia, racism) that constrain an individual's agency, particularly related to health outcomes [5]. While studies about HIV risk and SM-FSW are limited, data indicate that sexual minority women (SMW) are more likely to engage in sex work and experience disparate amounts of structural vulnerability (e.g., housing insecurity, violence) and therefore have worse HIV risk outcomes than their heterosexual counterparts [2-4].

Current best practices on conceptualizing and measuring sexual orientation incorporate a three dimensional model including identity, behavior, and attraction [6, 7]. Identity is self-defined based on how one identifies their sexual orientation. Behavior concerns the gender of sexual partners in relation to one's own gender. Attraction concerns the gender of those whom one is sexually attracted to, in relation to one's own gender, although attraction data were not collected in this study. Existing research indicates the merit of considering sexual minority populations as defined by both identity and behavior, as these dimensions of sexual orientation are not always overlapping and can reveal nuance in understanding the populations $[1,8]$. For this study, we use the term SMW to include both women who self-identify as gay, lesbian or bisexual, and/or women who have sex with women and men (WSWM). We specifically state SM-FSW by identity or by behavior when differentiating between the groups.

Structural vulnerabilities are both direct and indirect drivers of HIV [9-13]. Housing insecurity has known associations with sexual and physical victimization, substance use, exacerbated mental and physical health conditions [14-16], HIV risk [17-19], and poor HIV outcomes [20, 21]. Violence against women, in all its iterations, has a substantial impact on poor health, physical and sexual injury, substance use, mental health, and the acquisition of sexually transmitted infections (STI), including HIV [22-27].

FSW confront a combination of structural vulnerabilities, which both limit their ability to reduce harm and hinder their access to health services, including HIV prevention, thereby increasing their HIV and STI risk [12]. Globally, FSW lifetime prevalence of experiencing violence in the workplace ranged from 45 to $75 \%$ [27]; street-based sex workers experience particularly high levels of violence, including physical, verbal, and sexual abuse [28-30].

Additionally, FSW face various HIV risk drivers. Street-based sex work and drug use are intricately linked in many settings in the USA, where women who use drugs often sell sex to support their drug habits and may engage in high-risk injection or sexual practices with partners [31]. The shared criminalization of both drug use and sex work compounds the increased HIV prevalence rates by preventing care-seeking and HIV risk reduction. Additional FSW vulnerabilities and HIV risk drivers are also driven by sex work criminalization and include endurance of egregious police behaviors; violence victimization and work environments; inability to access drug treatment; imprisonment, poverty, and housing instability; and stigma and discrimination [30, 32-36].

Compared to heterosexual women, SMW face exacerbated HIV risks. Rates of HIV are higher in SMW who have sex with high-risk men, use drugs, and/or are sex workers [3]. SMW are more likely to report higher rates of alcohol and other substance use and dependence [3, 37-39]. Bisexual women are at increased odds for sexual abuse, intimate partner violence (IPV), and physical violence compared to heterosexual women [4]. Further, young SMW experience higher rates of violence [40], are more likely to be engaged in survival sex work [2, 41], and have higher HIV risk-related sex work practices, such as inconsistent condom use and a greater number of clients, than their heterosexual counterparts [2].

Research is lacking regarding SM-FSW, a population that is doubly marginalized due to their sexual orientation and their profession. We examine the differences in structural vulnerabilities and HIV risk drivers between SMW, by identity and behavior, and their heterosexual counterparts among street-based FSW in Baltimore City, MD, USA.

\section{Methods}

\section{Data source}

Data analyzed in this paper were collected as part of a larger research study, the Sex workers And Police Promoting Health In Risky Environments (SAPPHIRE) study-a prospective cohort of women involved in street-based sex work recruited between April 2016 and August 2017 in Baltimore City, MD, USA. SAPPHIRE's broad goal was to examine the role of the police in the HIV risk environment of street-based sex workers. A more detailed exploration of methods, including the study's novel targeted sampling methods, are available elsewhere [42, 43]. Briefly, locations were selected through mapping of arrest data and information collected through Baltimore City Police Department ridealongs. During 3-4-h recruitment periods, study staff approached single women who were visually soliciting clients. Eligibility criteria include the following: (1) age $\geq$ 15 years; (2) sold or traded oral, vaginal, or anal sex "for 
money or things like food, drugs, or favors"; (3) picked up clients on the street or at public places $\geq 3$ times in the past 3 months; and (4) willing to undergo HIV and STI testing. The exclusion criterion was identifying as male or a man.

Participants completed a 50-min interviewer-administered computer-assisted personal interview survey. The survey included sections on demographics, housing, finances, sex work history, police encounters, incarceration, sexual and drug use behaviors, health service access, childhood abuse, and mental health. Participants were also tested for HIV and STI. Participants received a pre-paid \$70 USD VISA gift card for completing the baseline survey. The study was approved by the Johns Hopkins Bloomberg School of Public Health Institutional Review Board.

\section{Study variables}

Survey items in the SAPPHIRE study were theoretically informed by the risk environment framework and the theory of structuration as well as drawn from existing validated scales, our previous studies $[5,44]$, and the expertise of the SAPPHIRE Community Advisory Board, a group comprised of current and former sex workers.

\section{Independent variables}

SM status was defined separately by identity and behavior. Participants were asked if they identified as heterosexual/straight, gay/lesbian, or bisexual; this variable was dichotomized to heterosexual vs. non-heterosexual (gay/ lesbian, or bisexual) ${ }^{1}$. Further, participants were asked about the gender of their sexual partners (vaginal or anal sex with a female client or regular partner in the past 3 months); this variable was dichotomized to heterosexual vs. non-heterosexual (WSWM).

\section{Confounding variables}

Age, race, and education were selected as control variables based on the literature and theoretical importance.

\section{Potential dependent variables}

Vulnerability variables included homelessness (past 3 months), arrest (lifetime), childhood abuse (sexual and physical), IPV (sexual and physical; lifetime), HIV, substance use (injection drug use [IDU], heroin, speedball, crack; past 3 months) and binge drinking (past 12 months) ${ }^{2}$, and sex work characteristic (minor at sex work entry, ever had a pimp/manager, years in sex work). Childhood ( $<18$ years old) abuse was defined as ever being pressured or forced into sexual intercourse or sexual

\footnotetext{
${ }^{1}$ Two additional response options, queer and same gender loving, received no responses.

${ }^{2}$ Additional drugs were tested but were not significant at the bivariate level (results not shown).
}

touching (sexual), or being hit, punched, slapped, or otherwise physically hurt by someone causing marks or physical injury (physical). IPV items were derived from the Revised Conflict Tactics Scale [45] and were defined as either (1) being hit, punched, slapped, or otherwise physically hurt, or being threatened or hurt with a weapon (physical), or (2) being involuntarily pressured or forced into sexual intercourse (sexual).

\section{Sample}

The analytic sample comprised 247 cisgender FSW. The sample excluded participants who identified as intersex $(n=1)$, did not have male or female clients in the past 3 months $(n=1)$, indicated being "confused" regarding sexual identity $(n=1)$, and had incomplete data on either the identity or behavior variables $(n=1)$.

\section{Statistical analyses}

Bivariate differences between the independent variables (SM-FSW by identity and by behavior) and potential dependent variables (structural vulnerabilities and HIV risk drivers) were compared using Pearson's chi-square tests for categorical variables and simple linear regression for the continuous variable (the age variable did not pass the Shapiro-Wilk normality test), with $p<0.100$ indicating statistical significance.

Covariates significant $p<0.100$ at the bivariate level were entered in the multivariable logistic regression models as dependent variables and SM status as independent variables. Multivariable models accounted for clustering within the zone of recruitment and controlled for age, race, and education. A total of 14 models are included. For example, homelessness was significant at the bivariate level for both classifications of SM status; for the multivariable model, two separate models were run for the same dependent variable: model 1 included control variables and SM status by behavior as independent variables and homelessness as dependent; model 2 included control variables and SM status by identity as independent variables and homelessness as dependent. This process was repeated for all covariates significant at the bivariate level. We report adjusted odds ratios (AOR) and 95\% confidence intervals (CI). All analyses were conducted using Stata MP 15 software (StataCorp).

\section{Results}

Roughly one quarter (25.5\%) of participants reported SM status by identity and $8.5 \%$ by behavior (see Table 1 ). Of those who reported SM identity, 70\% reported sex with men only and $30 \%$ reported sex with women and men in the past 3 months. Only 2 heterosexual-identified women reported sex with women.

The sample was $66 \%$ white, with a mean age of 35.7 , and $53 \%$ reported having less than a 12th-grade 
Table 1 SM-FSW by identity and behavior (past 3 months)

\begin{tabular}{|c|c|c|c|c|}
\hline & & \multicolumn{2}{|c|}{ SMW by behavior } & \multirow[t]{2}{*}{ Total } \\
\hline & & WSMO* & WSWM ${ }^{*}$ & \\
\hline \multirow[t]{3}{*}{ SMW by identity } & Heterosexual identified & $182(80.53 \%)$ & $2(9.52 \%)$ & $184(74.49 \%)$ \\
\hline & Gay or bisexual identified & $44(19.47 \%)$ & $19(90.48 \%)$ & $63(25.51 \%)$ \\
\hline & Total & $226(100 \%)$ & 21 (100\%) & 247 (100\%) \\
\hline
\end{tabular}

WSMO- women who report sex with men only, WSWM- women who report sex with women and men

*Past 3 months

education. Rates of current homelessness (62.8\%), previous arrest (82.2\%) and incarceration (69.8\%), childhood violence (33.5\% sexual, $42 \%$ physical), IPV (24.3\% sexual, $47.5 \%$ physical), substance use (70.4\% IDU, $24 \%$ binge drinking), depression (85.5\%), and PTSD (60.8\%) were all high. HIV prevalence was $5.3 \%$. Half of the sample $(51.8 \%)$ had been engaging in sex work for more than 5 years (Table 2).

\section{SM-FSW by identity}

Compared to heterosexual FSW, SM-FSW by identity were younger (33.8 vs. $36.3 ; p=0.06)$ and reported elevated rates of homelessness $(74.6 \%$ vs. $58.7 \%$; $p=0.02)$, physical IPV (59.7\% vs. $43.3 \%$; $p=0.02)$, IDU (79.4 \% vs. $67.4 \% ; p=0.07)$, and speedball injection $(30.2 \%$ vs. $20.2 \% ; p=0.10)$. SM-FSW by identity were more likely to report being a minor at age of sex work initiation (36.5\% vs. $16.3 \% ; p<0.001$ ) and ever having a pimp/ manager (15.9\% vs. $7.1 \%$; $p=0.04)$ (Table 2$)$.

In adjusted models (Table 3), SM-FSW by identity were at greater odds than heterosexually identified FSW to have reported homelessness $(\mathrm{aOR}=1.89,95 \% \mathrm{CI}$ $1.11-3.23, p=0.02)$, physical IPV $(\mathrm{aOR}=2.00,95 \% \mathrm{CI}$ $1.29-3.12, p=0.002)$, injection drug use $(\mathrm{aOR}=2.29$, $95 \%$ CI 1.17-4.48, $p=0.02$ ), binge drinking ( $\mathrm{aOR}=1.99$, 95\% CI 1.49-2.67, $p<0.001$ ), and beginning sex work as a minor $(\mathrm{aOR}=2.60,95 \% \mathrm{CI} 1.50-4.51, p=0.001)$.

\section{SM-FSW by behavior}

Compared to heterosexual FSW, SM-FSW by behavior were less likely to be white $(42.9 \%$ vs. $68.1 \%$; $p=0.02)$ and more likely not to have completed high school $(71.4 \%$ vs. 51.3; $p=0.08)$. SM-FSW by behavior reported elevated levels of homelessness ( $81 \%$ vs $61 \% ; p=0.071)$, binge drinking (52.4\% vs. $32.3 \%$; $p=0.06)$, being a minor at age of sex work initiation $(57.1 \%$ vs. $18.1 \% ; p<0.001)$, and ever having a pimp/manager $(23.8 \%$ vs. $8 \% ; p=0.02)$ (Table 2).

In adjusted models (Table 3), SM-FSW by behavior were at greater odds than women who have sex with men only (WSMO) to have reported homelessness (aOR $2.64,95 \%$ CI 1.24-5.57, $p=0.01)$, binge drinking (aOR = 2.80, 95\% CI 1.77-4.44, $p<0.001$ ), ever having a pimp $(\mathrm{aOR}=3.36,95 \% \mathrm{CI} 1.94-5.74, p<0.001)$, and beginning sex work as a minor $(\mathrm{aOR}=4.82,95 \% \mathrm{CI}$ $2.68-8.68, p<0.001)$.

\section{Discussion}

This study is one of the first to explore the association between SM status, by identity and by behavior, and structural vulnerabilities and HIV risk among streetbased FSW. While FSW are characterized by significant structural vulnerabilities and HIV risk, we found these outcomes exacerbated among SM-FSW, by both identity and behavior, including substance use, homelessness, physical IPV, entering sex work as a minor, or ever having a pimp. Our results have important implications for improving HIV prevention and overall health promotion initiatives to better meet the needs of SM-FSW and to drive additional research endeavors.

The overall trends in our study tell a story of increased vulnerability among SM-FSW, with differences between the identity and behavior groups regarding IDU and physical IPV, both of which were significantly higher for SM-FSW by identity but not behavior. These differences support considering multiple dimensions of sexual orientation among the high-risk groups of women, similar to previous work [1, 46]. Findings also suggest that identity-related factors, such as stigma and discrimination, might explain some heightened risk. The minority stress theory $[47,48]$ posits that people with marginalized identities face exacerbated stressors from stigma and discrimination that accrue over time and lead to long-term health deficits. Coping with minority stress may occur through a range of maladaptive mechanisms, including IDU and increased violence exposure.

The results indicate an increased likelihood of two substance use behaviors, IDU and binge drinking, corroborating existing literature regarding substance use disparities among a general SMW population. The HIV risk implications of IDU are well-documented $[49,50]$. The increased rates of IDU among SM-FSW by identity (79.4\%) differed from a 2015 Baltimore study focusing on female IDUs, who also reported high rates of sex exchange (35\%) [1]. SMW are more likely to report binge drinking compared to their heterosexual counterparts [51-53]. A relationship has been found between SM-related rejection and increased alcohol use [54]. Aside from the direct health consequences, binge 
Table 2 SM-FSW characteristics by identity and behavior

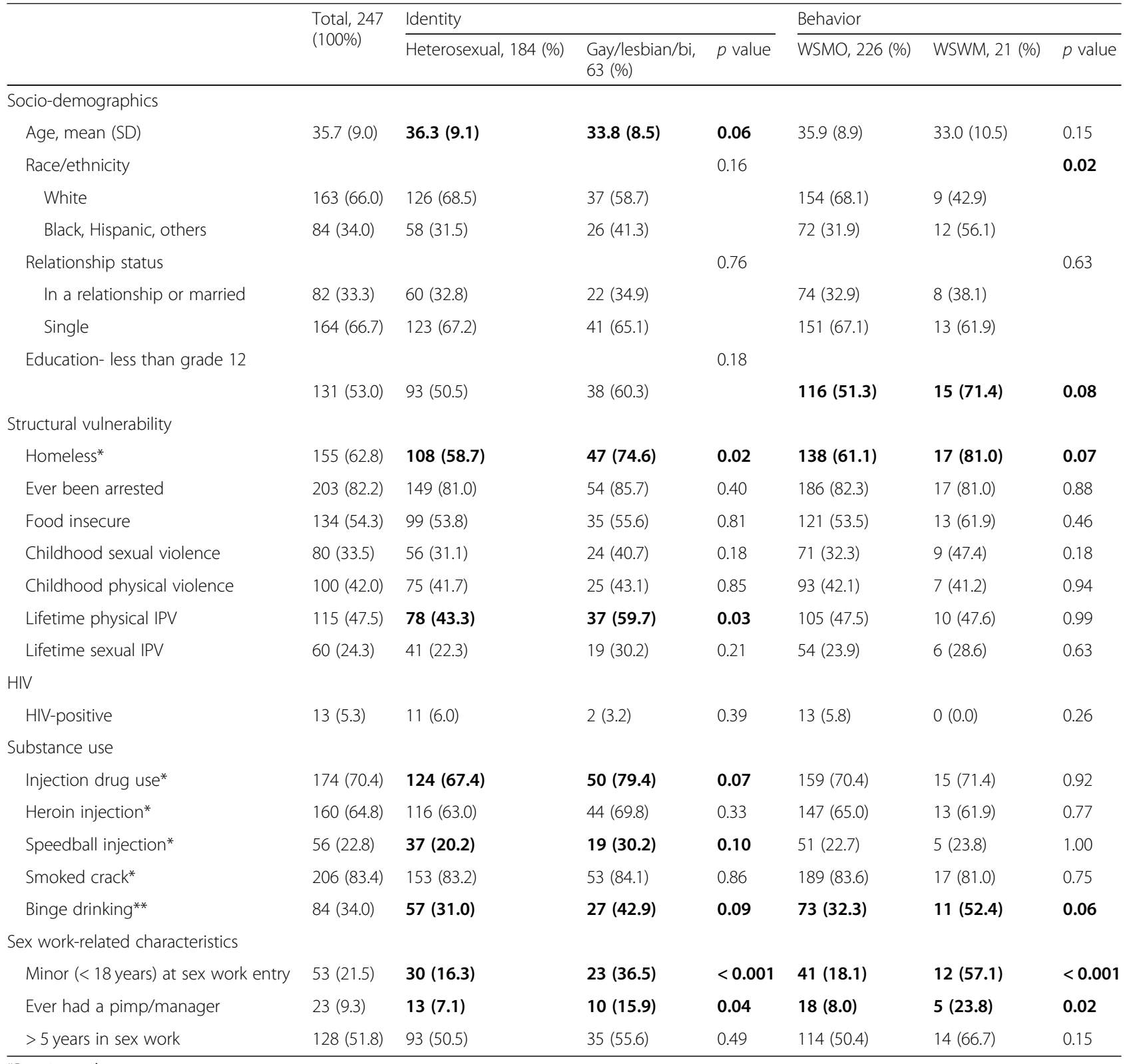

*Past 3 months

**Past 12 months

drinking is associated with transactional sex engagement among a general population of women $[55,56]$ and unprotected sex, sexual violence, and STI rates among FSW [55, 56]. Minority stress may explain elevated substance use as a means of coping. HIV prevention programs targeting FSW must work in collaboration with harm reduction and substance use treatment programs, with a special attention to SMW. We are not aware of programs currently doing this work. Further, as sexual minority women have been largely considered "not at risk" of HIV, they have not benefited from mainstream HIV prevention programming, albeit few target FSW in the USA.

The exacerbated likeliness of homelessness among SM-FSW points to the depth of structural vulnerability in this population. Homelessness is associated with a range of deleterious health outcomes, including elevated rates of HIV [57]. SMW, regardless of sex work involvement, have increased rates of homelessness [58] due to family conflict, stigma, and sexual abuse [59, 60]. Homeless SM youth are more likely to engage in lifetime survival sex and sex with an HIV-positive partner [61]. Taken together, these data underscore the importance of 
Table 3 Multivariable associations between SM-FSW status and structural vulnerabilities - GEE logistic regression with variance clustering for zone (adjusted odds ratios and 95\% confidence intervals)

\begin{tabular}{|c|c|c|c|}
\hline & $\mathrm{aOR}$ & $95 \% \mathrm{Cl}$ & $p$ value \\
\hline \multicolumn{4}{|l|}{ Injection drug use* } \\
\hline SMW by identity & 2.29 & $1.17-4.48$ & 0.016 \\
\hline SMW by behavior & 1.49 & $0.41-5.42$ & 0.544 \\
\hline \multicolumn{4}{|l|}{ Injection speedball* } \\
\hline SMW by identity & 1.72 & $0.79-3.72$ & 0.238 \\
\hline SMW by behavior & 1.08 & $0.33-3.54$ & 0.327 \\
\hline \multicolumn{4}{|l|}{ Binge drinking** } \\
\hline SMW by identity & 1.99 & $1.49-2.67$ & $<0.001$ \\
\hline SMW by behavior & 2.80 & $1.77-4.44$ & $<0.001$ \\
\hline \multicolumn{4}{|l|}{ Homeless* } \\
\hline SMW by identity & 1.89 & $1.11-3.23$ & 0.019 \\
\hline SMW by behavior & 2.64 & $1.25-5.57$ & 0.011 \\
\hline \multicolumn{4}{|l|}{ Physical IPV*** } \\
\hline SMW by identity & 2.00 & $1.29-3.12$ & 0.002 \\
\hline SMW by behavior & 1.03 & $0.41-2.61$ & 0.95 \\
\hline \multicolumn{4}{|l|}{ Ever had a pimp } \\
\hline SMW by identity & 2.23 & $0.94-5.33$ & 0.070 \\
\hline SMW by behavior & 3.36 & $1.94-5.74$ & $<0.001$ \\
\hline \multicolumn{4}{|c|}{ Minor at sex work entry (age < 18) } \\
\hline SMW by identity & 2.60 & $1.50-4.51$ & 0.001 \\
\hline SMW by behavior & 4.82 & $2.68-8.68$ & $<0.001$ \\
\hline
\end{tabular}

aOR adjusted for respondent age, race, and education

*Past 3 months

**Past 12 months

*** Lifetime

focusing on SM status when designing HIV prevention and housing security interventions for FSW. These points are particularly relevant for working with younger populations.

SM individuals experience higher rates of violence victimization than heterosexuals across the life course $[40,62]$. Elevated rates of IPV are associated with race, socio-economic status [63], and expectations of prejudice and discrimination $[64,65]$. Internalized homophobia, resulting from minority stress, is linked to IPV perpetration and victimization [66]. We found that SMFSW by identity have higher odds of physical IPV compared to their heterosexual counterparts, aligning with previous research among a general SMW population $[67,68]$, indicating unique vulnerability related to sexual minority status. Further, barriers to existing IPV services include a limited understanding of SM IPV, stigma, and systemic inequities [69]. SM-FSW face unique and exacerbated IPV vulnerabilities further intensified at the intersections of additional marginalized identities (i.e., race, class). Violence prevention programs should increase the utilization of a sexual orientation lens in their work, which could include gender and sexuality sensitivity training for staff, sexual minority-targeted outreach and programming, and policy-level work incorporating the needs of SM-FSW.

The increased odds of early sex work engagement and having a pimp among SM-FSW, found above, have not previously been explored. Research investigating health outcomes of domestic sex-trafficked victims ${ }^{3}$ regardless of sexual orientation indicates significantly worse health outcomes than that of non-trafficked women engaging in sex work, including physical health, suicidal ideation, substance use disorders, and healthcare deprivation [70, 71]. Sex work experiences are associated with drug and/ or alcohol addiction, co-occurring illnesses, suicidal ideation, workplace violence, and condom non-use and failure [70, 71]. Having an abusive pimp is associated with co-occurring illnesses, poor overall physical and mental health, and suicidal ideation [70]. In sum, SMFSW face increased risk vulnerability, particularly related to violence victimization throughout the life course, and may, again, be tied to minority stress and stigma related to their sexual minority status.

We found higher rates of SM status by both identity and behavior among our sample of FSW, compared to women in a generalized population study. A quarter (25.5\%) of our sample identified as lesbian or bisexual, and $8.5 \%$ reported sex with women and men in the last 3 months. These data are much higher than women in a general population sample $(1.5 \%$ lesbian/bisexual identified, $2 \%$ lifetime both-gender behavior) [37], indicating a relationship between SM status and sex work engagement, also found elsewhere [72]. LGBT young people frequently face family rejection, which impacts substance use, social support access, mental health, and homelessness $[61,73]$. Coupled with the higher likelihood of sex work engagement risk behaviors among SM-FSW, we hypothesize that early life adversity related to SM status drives sex work engagement among SMW.

\section{Limitations}

These results should be considered in light of several limitations. First, the construction of the SM variables was limited. The sexual behavior question was asked within a 3-month time period, so would not have captured women who have sex with other women, but who have not done so recently. Further, the category includes both regular partners and clients, which may mask differences in women who have sex with various genders in the working context vs. in their personal life. Data were

${ }^{3}$ Women who entered the sex trade due to coercion, fraud, etc. and/or before the age of 18 . 
not available regarding attraction, so this dimension of sexual orientation was not examined. Second, to address small cell sizes, we utilized a binary race variable, white and people of color (POC); therefore, we were unable to assess the differences among POC. More research is needed to better examine the differences across race, a known HIV vulnerability driver, and sexual orientation. Further, we were limited in looking at specific SM identities. Bisexual women are known to have a unique risk profile from their lesbian counterparts [74]; future research may identify further disparity risk profiles among SM-FSW subgroups. Last, this analysis was conducted only among the cisgender women in the SAPPHIRE study. The assumption of binary gender excludes gender non-binary individuals, who may have unique risk profiles.

\section{Conclusion}

Our results indicate that SM-FSW experience exacerbated structural vulnerabilities and HIV risk drivers, as compared to their heterosexual FSW counterparts, a group that already experiences high rates of structural and HIVrelated vulnerabilities. SM-FSW are a high-risk group within a high-risk group. This multiple marginalization is likely further exacerbated when considering young women. FSW-focused interventions must consider the unique needs of SMW and develop trauma-informed multi-level harm reduction programs, which can simultaneously address the complex constellation of structural and HIV risk faced by these women. This is particularly important for younger women, for whom opportunities to intervene early may protect against exacerbated vulnerability across the life course. People in all social service programming (i.e., substance use, housing support, violence prevention, sex worker advocacy, anti-trafficking, and sex work alternatives) need to understand SMW's unique exacerbated risks. More research surrounding SM-FSW unique experiences is necessary to inform customized HIV prevention and overall health promotion interventions for this population.

\section{Abbreviations \\ AOR: Adjusted odds ratios; Cl: Confidence intervals; FSW: Female sex workers; HIV: Human immunodeficiency virus; IDU: Injection drug use; IPV: Intimate partner violence; LGBT: Lesbian, gay, bisexual, transgender; POC: People of color; PTSD: Posttraumatic stress disorder; SAPPHIRE: Sex workers And Police Promoting Health In Risky Environments study; SM: Sexual minority; SMW: Sexual minority women; SM-FSW: Sexual minority female sex workers; STI: Sexually transmitted infections; WSWM: Women who have sex with women and men; WSWO: Women who have sex with women only}

\section{Acknowledgements}

The authors would like to thank all of the women who participated in the SAPPHIRE study and the larger SAPPHIRE research team. We express deep appreciation to Lena Sinha, MPH, for reviewing the manuscript draft and providing indispensable insight.

\section{Authors' contributions}

SGS designed the Sex workers And Police Promoting Health In Risky Environments (SAPPHIRE) study and was the study PI. JNP supported the protocol development and conducted the data management. JG and SL conceptualized the research question and analytical approach for this manuscript. SL conducted the analyses. JG drafted the manuscript and incorporated suggestions from all co-authors. SL, JNP, SWB, CT, and SS critically revised the manuscript and contributed important intellectual content. All authors reviewed and approved the final version of the manuscript.

\section{Funding}

This work was supported by the National Institute on Drug Abuse (R01DA038499-01), the Drug Dependence Epidemiology Training Program, $\mathrm{NIH/NIDA}$ (T32DA007292), and Johns Hopkins University Center for AIDS Research (1P30Al094189).

\section{Availability of data and materials}

The datasets generated and/or analyzed during the current study are not publicly available in order to protect participant confidentiality but are available from the corresponding author on reasonable request.

\section{Ethics approval and consent to participate}

The study was approved by the Johns Hopkins Bloomberg School of Public Health Institutional Review Board.

\section{Consent for publication}

Not applicable

\section{Competing interests}

Susan Sherman is an expert witness in opioid legislation on the plaintiff's side.

\section{Author details}

'Department of Health Behavior and Society, Johns Hopkins Bloomberg School of Public Health, Baltimore, MD 21205, USA. ${ }^{2}$ Department of Population Health, NYU School of Medicine, New York, NY, USA.

Received: 30 September 2019 Accepted: 26 May 2020

Published online: 15 June 2020

\section{References}

1. German D, Latkin CA. HIV risk, health, and social characteristics of sexual minority female injection drug users in Baltimore. AIDS and Behavior. 2015; 19(7):1361-5.

2. Marshall BD, Shannon K, Kerr T, Zhang R, Wood E. Survival sex work and increased HIV risk among sexual minority street-involved youth. Journal of Acquired Immune Deficiency Syndromes (1999). 2010;53(5):661.

3. Roberts SJ. Health care of sexual minority women. Nurs Clin North Am. 2018;53(2):227-39.

4. Pyra M, Weber K, Wilson TE, Cohen J, Murchison L, Goparaju L, et al. Sexual minority status and violence among HIV infected and at-risk women. 2014; 29(8):1131-1138.

5. Brantley ML, Kerrigan D, German D, Lim S, Sherman SG. Identifying patterns of social and economic hardship among structurally vulnerable women: a latent class analysis of HIV/STI risk. AIDS and Behavior. 2017;21(10):3047-56.

6. Badgett M. Best practices for asking questions about sexual orientation on surveys. 2009.

7. Io M. The health of lesbian, gay, bisexual, and transgender people: building a foundation for better understanding. DC: National Academies Press Washington; 2011

8. Young RM, Meyer $\mathbb{H}$. The trouble with "MSM" and "WSW": erasure of the sexual-minority person in public health discourse. American Journal of Public Health. 2005;95(7):1144-9.

9. Garcia-Moreno C, Watts C. Violence against women: an urgent public health priority. Bulletin of the World Health Organization. 2011;89:2.

10. Milloy MJ, Marshall BD, Kerr T, Buxton J, Rhodes T, Montaner J, et al. Social and structural factors associated with HIV disease progression among illicit drug users: a systematic review. AIDS. 2012;26(9):1049-63. 
11. Shannon K, Kerr T, Allinott S, Chettiar J, Shoveller J, Tyndall MW. Social and structural violence and power relations in mitigating HIV risk of drug-using women in survival sex work. Soc Sci Med. 2008;66(4):911-21.

12. Gupta GR, Parkhurst JO, Ogden JA, Aggleton P, Mahal A. Structural approaches to HIV prevention. Lancet. 2008;372(9640):764-75.

13. El-Bassel N, Shaw SA, Dasgupta A, Strathdee SA. Drug use as a driver of HIV risks: re-emerging and emerging issues. Curr Opin HIV AIDS. 2014;9(2):150-5.

14. Hwang SWJC. Homelessness and health. 2001;164(2):229-33.

15. Johnstone M, Jetten J, Dingle GA, Parsell C, Walter ZCJFip. Discrimination and well-being amongst the homeless: the role of multiple group membership. 2015;6:739

16. Davey-Rothwell MA, German D, Latkin CA. Residential transience and depression: does the relationship exist for men and women? Journal of Urban Health. 2008:85(5):707-16.

17. German D, Davey MA, Latkin CA. Residential transience and HIV risk behaviors among injection drug users. AIDS and Behavior. 2007;11(2):21-30.

18. Gangamma R, Slesnick N, Toviessi P, Serovich J. Comparison of HIV risks among gay, lesbian, bisexual and heterosexual homeless youth. J Youth Adolesc. 2008;37(4):456-64.

19. Ebner DL, Laviage MM. The parallel universe of homeless and HIV-positive youth. Semin Pediatr Infect Dis. 2003;14(1):32-7.

20. Buchanan D, Kee R, Sadowski LS, Garcia DJAJoPH. The health impact of supportive housing for HIV-positive homeless patients: a randomized controlled trial. 2009;99(S3):S675-SS80.

21. Aidala AA, Lee G, Abramson DM, Messeri P, Siegler AJA, Behavior. Housing need, housing assistance, and connection to HIV medical care. 2007;11(2): 101-115.

22. Campbell JC. Health consequences of intimate partner violence. The lancet. 2002:359(9314):1331-6.

23. Caetano R, Cunradi C. Intimate partner violence and depression among Whites, Blacks, and Hispanics. Annals of Epidemiology. 2003;13(10):661-5.

24. Golding JM. Intimate partner violence as a risk factor for mental disorders: a meta-analysis. Journal of Family Violence. 1999;14(2):99-132.

25. Campbell JC, Baty M, Ghandour RM, Stockman JK, Francisco L, Wagman J. The intersection of intimate partner violence against women and HIV/AIDS: a review. International Journal of Injury Control and Safety Promotion. 2008; 15(4):221-31.

26. Silverman JG, Gupta J, Decker MR, Kapur N, Raj A. Intimate partner violence and unwanted pregnancy, miscarriage, induced abortion, and stillbirth among a national sample of Bangladeshi women. BJOG: An International Journal of Obstetrics \& Gynaecology. 2007;114(10):1246-52.

27. Deering KN, Amin A, Shoveller J, Nesbitt A, Garcia-Moreno C, Duff P, et al. A systematic review of the correlates of violence against sex workers. American Journal of Public Health. 2014;104(5):e42-54.

28. Church S, Henderson M, Barnard M, Hart G. Violence by clients towards female prostitutes in different work settings: questionnaire survey. BMJ. 2001:322(7285):524-5.

29. Footer KH, Park JN, Allen ST, Decker MR, Silberzahn BE, Huettner S, et al. Police-related correlates of client-perpetrated violence among female sex workers in Baltimore City. Maryland. American Journal of Public Health. 2019;109(2):289-95.

30. Goldenberg SM, Duff P. Krusi AJBph. Work environments and HIV prevention: a qualitative review and meta-synthesis of sex worker narratives 2015;15(1):1241

31. Cleland CM, Des Jarlais DC, Perlis TE, Stimson G, Poznyak V. Group WHOPIDICS. HIV risk behaviors among female IDUs in developing and transitional countries. BMC Public Health. 2007;7:271.

32. Shannon K, Kerr T, Strathdee SA, Shoveller J, Montaner JS, Tyndall MW Prevalence and structural correlates of gender based violence among a prospective cohort of female sex workers. BJM. 2009;339:b2939.

33. Footer $\mathrm{KH}$, Silberzahn BE, Tormohlen KN, Sherman SG. Policing practices as a structural determinant for HIV among sex workers: a systematic review of empirical findings. Journal of the International AIDS Society. 2016;19:20883.

34. El-Bassel N, Shaw SA, Dasgupta A, Strathdee SA. Drug use as a driver of HIV risks: re-emerging and emerging issues. Current Opinion in HIV and AIDS. 2014;9(2):150.

35. Campbell R, Kinnell H. "We shouldn't have to put up with this": street sex work and violence; 2000.

36. Des Jarlais DC, Feelemyer JP, Modi SN, Arasteh K, Hagan H. Are females who inject drugs at higher risk for HIV infection than males who inject drugs: an international systematic review of high seroprevalence areas. Drug \& Alcohol Dependence. 2012;124(1):95-107.

37. McCabe SE, Hughes TL, Bostwick WB, West BT, Boyd CJ. Sexual orientation, substance use behaviors and substance dependence in the United States. Addiction. 2009;104(8):1333-45.

38. Boyd CJ, Veliz PT, Stephenson R, Hughes TL, McCabe SE. Severity of alcohol, tobacco, and drug use disorders among sexual minority individuals and their "not sure" counterparts. LGBT Health. 2019;6(1):15-22.

39. Green KE, Feinstein BA. Substance use in lesbian, gay, and bisexual populations: an update on empirical research and implications for treatment. Psychol Addict Behav. 2012;26(2):265-78.

40. Schwab-Reese LM, Currie D, Mishra AA, Peek-Asa C. A comparison of violence victimization and polyvictimization experiences among sexual minority and heterosexual adolescents and young adults. J Interpers Violence. 2018:0886260518808853.

41. Weber AE, Boivin JF, Blais L, Haley N, Roy E. Predictors of initiation into prostitution among female street youths. J Urban Health. 2004;81(4):584-95.

42. Allen ST, Footer KH, Galai N, Park JN, Silberzahn B, Sherman SG. Implementing targeted sampling: lessons learned from recruiting female sex workers in Baltimore. MD. Journal of Urban Health. 2018:1-10.

43. Sherman SG, Park JN, Galai N, Allen ST, Huettner SS, Silberzahn BE, et al. Drivers of HIV infection among cisgender and transgender female sex worker populations in Baltimore City: results from the SAPPHIRE study. JAIDS Journal of Acquired Immune Deficiency Syndromes. 2019; 80(5):513-21.

44. Reilly ML, German D, Serio-Chapman C, Sherman SG. Structural vulnerabilities to HIV/STI risk among female exotic dancers in Baltimore Maryland. AIDS Care. 2015;27(6):777-82.

45. Straus MA, Hamby SL, Boney-McCoy S, Sugarman DB. The revised conflict tactics scales (CTS2) development and preliminary psychometric data. Journal of Family Issues. 1996;17(3):283-316.

46. Paschen-Wolff MM, Kelvin E, Wells BE, Campbell AN, Grosskopf NA, Grov C. Changing trends in substance use and sexual risk disparities among sexual minority women as a function of sexual identity, behavior, and attraction: findings from the National Survey of Family Growth. Archives of sexual behavior. 2002-2015;2019:1-22.

47. Brooks VR. Minority stress and lesbian women: Lexington Books Lexington, MA; 1981.

48. Meyer $\mathrm{H}$. Minority stress and mental health in gay men. Journal of Health and Social Behavior. 1995:36(1):38-56.

49. Des Jarlais DC, Arasteh K, Perlis T, Hagan H, Abdul-Quader A, Heckathorn $D D$, et al. Convergence of HIV seroprevalence among injecting and noninjecting drug users in New York City. AIDS. 2007;21(2):231-5.

50. Campbell AN, Tross S, Calsyn DA. Substance use disorders and HIV/AIDS prevention and treatment intervention: research and practice considerations. Soc Work Public Health. 2013;28(3-4):333-48.

51. Pharr JR, Kachen A, Cross C. Health disparities among sexual gender minority women in the United States: a population-based study. Journal of Community Health. 2019:1-8.

52. Coulter RW, Jun HJ, Calzo JP, Truong NL, Mair C, Markovic N, et al. Sexualorientation differences in alcohol use trajectories and disorders in emerging adulthood: results from a longitudinal cohort study in the United States. Addiction. 2018:113(9):1619-32.

53. Fish JN, Hughes TL, Russell ST. Sexual identity differences in high-intensity binge drinking: findings from a US national sample. Addiction. 2018;113(4): 749-58.

54. Rosario M, Schrimshaw EW, Hunter J. Disclosure of sexual orientation and subsequent substance use and abuse among lesbian, gay, and bisexual youths: critical role of disclosure reactions. Psychology of Addictive Behaviors. 2009;23(1):175.

55. Magni S, Christofides N, Johnson S, Weiner R. Alcohol use and transactional sex among women in South Africa: results from a Nationally Representative Survey. Plos One. 2015;10(12):e0145326.

56. Chersich M, Luchters S, Malonza I, Mwarogo P, King'Ola N, Temmerman M. Heavy episodic drinking among Kenyan female sex workers is associated with unsafe sex, sexual violence and sexually transmitted infections. International Journal of STD \& AIDS. 2007;18(11):764-9.

57. Culhane DP, Gollub E, Kuhn R, Shpaner M. The co-occurrence of AIDS and homelessness: results from the integration of administrative databases for AIDS surveillance and public shelter utilisation in Philadelphia. J Epidemiol Community Health. 2001;55(7):515-20. 
58. Flentje A, Leon A, Carrico A, Zheng D, Dilley J. Mental and physical health among homeless sexual and gender minorities in a major urban US city. J Urban Health. 2016;93(6):997-1009.

59. Cochran BN, Stewart AJ, Ginzler JA, Cauce AM. Challenges faced by homeless sexual minorities: comparison of gay, lesbian, bisexual, and transgender homeless adolescents with their heterosexual counterparts. Am J Public Health. 2002;92(5):773-7.

60. Rew L, Whittaker TA, Taylor-Seehafer MA, Smith LR. Sexual health risks and protective resources in gay, lesbian, bisexual, and heterosexual homeless youth. J Spec Pediatr Nurs. 2005;10(1):11-9.

61. Gattis MN. An ecological systems comparison between homeless sexual minority youths and homeless heterosexual youths. I Soc Serv Res. 2013; 39(1):38-49.

62. Andersen JP, Zou C, Blosnich J. Multiple early victimization experiences as a pathway to explain physical health disparities among sexual minority and heterosexual individuals. Social Science \& Medicine. 2015;133:111-9.

63. Steele SM, Everett BG, Hughes TL. Influence of perceived femininity, masculinity, race/ethnicity, and socioeconomic status on intimate partner violence among sexual-minority women. Journal of Interpersonal Violence. 2017;0886260516683176.

64. Carvalho AF, Lewis RJ, Derlega VJ, Winstead BA, Viggiano C. Internalized sexual minority stressors and same-sex intimate partner violence. Journal of Family Violence. 2011;26(7):501-9.

65. Edwards KM, Sylaska KM, Neal AM. Intimate partner violence among sexual minority populations: a critical review of the literature and agenda for future research. Psychology of Violence. 2015;5(2):112.

66. Badenes-Ribera L, Sánchez-Meca J, Longobardi C. The relationship between internalized homophobia and intimate partner violence in same-sex relationships: a meta-analysis. Trauma, Violence, \& Abuse. 2017; 1524838017708781.

67. Walters $M$, Chen J, Breiding M. National Intimate Partner and Sexual Violence Survey 2010: findings on victimization by sexual orientation. 2011.

68. Sutter ME, Rabinovitch AE, Trujillo MA, Perrin PB, Goldberg LD, Coston BM, et al. Patterns of intimate partner violence victimization and perpetration among sexual minority women: a latent class analysis. Violence Against Women. 2019;25(5):572-92.

69. Calton JM, Cattaneo LB, Gebhard KT. Barriers to help seeking for lesbian, gay, bisexual, transgender, and queer survivors of intimate partner violence. Trauma, Violence, \& Abuse. 2016;17(5):585-600

70. Muftić LR, Finn MA. Health outcomes among women trafficked for sex in the United States: a closer look. Journal of Interpersonal Violence. 2013; 28(9):1859-85.

71. Decker MR, McCauley HL, Phuengsamran D, Janyam S, Silverman JG. Sex trafficking, sexual risk, sexually transmitted infection and reproductive health among female sex workers in Thailand. Journal of Epidemiology \& Community Health. 2011;65(4):334-9.

72. Lim S, Brantley ML, Footer K, Nail JE, Davis W, Sherman SG. Psychosocial characteristics and sexual risk behaviors among female exotic dancers who have sex with women in Baltimore: a brief report. Journal of Bisexuality. 2017:17(3):318-24.

73. Puckett JA, Woodward EN, Mereish EH, Pantalone DW. Parental rejection following sexual orientation disclosure: impact on internalized homophobia, social support, and mental health. LGBT Health. 2015;2(3):265-9.

74. Simoni JM, Smith L, Oost KM, Lehavot K, Fredriksen-Goldsen K. Disparities in physical health conditions among lesbian and bisexual women: a systematic review of population-based studies. Journal of Homosexuality. 2017:64(1):32-44.

\section{Publisher's Note}

Springer Nature remains neutral with regard to jurisdictional claims in published maps and institutional affiliations.

Ready to submit your research? Choose BMC and benefit from:

- fast, convenient online submission

- thorough peer review by experienced researchers in your field

- rapid publication on acceptance

- support for research data, including large and complex data types

- gold Open Access which fosters wider collaboration and increased citations

- maximum visibility for your research: over $100 \mathrm{M}$ website views per year

At BMC, research is always in progress.

Learn more biomedcentral.com/submissions 